\title{
La alternancia y la política exterior en México
}

$\mathrm{M}$ éxico dista de ser un país de extremos. Ya sea en términos de desarrollo humano, corrupción, productividad o hasta desempeño futbolístico, el país parece destinado a la media tabla. Tal ha sido el caso también del proceso de transición democrática. Es difícil encontrar momentos fundacionales, como el Pacto de la Moncloa, o quiebres institucionales drásticos, como la deserción presidencial, en la larga trayectoria de nuestro país hacia la normalidad democrática. La mexicana ha sido, pues, una transición aburrida. Aburrida, sí, pero relativamente estable; baste un dato para abonar el punto de la relativa estabilidad: tenemos la misma constitución de hace 89 años. La transición tardó aproximadamente tres décadas en gestarse, y puede sostenerse que estaba dada aún antes de que la oposición tomara el poder - las elecciones de 1997 tuvieron lugar con una autoridad electoral autónoma, y de ella emanó una división real de poderes-. Una prueba más de lo prolongado y anticlimático del periplo de muda de régimen, no obstante los importantes efectos de la alternancia de partidos, lo provee la política exterior del gobierno de Vicente Fox. Los siguientes párrafos exploran someramente los fundamentos de esta aseveración.

* Profesor-investigador del Departamento de Estudios del Pacífico de la Universidad de Guadalajara, y miembro del sNI.
Mucha tinta y saliva se ha empleado en discutir si la política exterior del gobierno foxista representa continuidad o cambio respecto a la del "ancien régime". Hay quienes argumentan, por ejemplo, que los votos contra Cuba en materia de derechos humanos representan un cambio, para mal, de la orgullosa tradición no intervencionista de la diplomacia mexicana. Otros sostienen que a pesar de que el nuevo gobierno quiso innovar en algunos aspectos de la política exterior, tales como la participación en el Consejo de Seguridad de la Organización de las Naciones Unidas (ONU) o su involucramiento como mediador en el conflicto colombiano, al final del día prevaleció la sabiduría institucional depositada - hasta hace poco cuando la cancillería se mudó- en Tlatelolco. Por supuesto que ambas posiciones son incorrectas o, si se quiere, parcialmente correctas. Elementos tanto de cambio como de continuidad han estado presentes en la diplomacia del gobierno de Fox. Ningún país - y México, en particular - se reinventa en seis años, de la misma manera que difícilmente una nación que vive un cambio tan significativo como lo es el que el partido que ha estado en el poder durante décadas — siete, en nuestro caso- deje el poder, se abstendrá de reflejarlo en su interacción internacional.

Revisemos brevemente la agenda exterior del presidente Fox. Cabe destacar que ésta era una de las pocas áreas en las que el equipo de campaña del guanajuatense 
La alternancia y la política exterior en México

había hecho la tarea, y tenía propuestas concretas e innovadoras. Así, por ejemplo, la plataforma electoral aprobada por el Partido Acción Nacional afirmaba que México debía jugar un papel más activo en la política mundial. Más concretamente, la propuesta de política exterior elaborada por Agustín Gutiérrez Canet y Martha Bárcena, ambos miembros del servicio exterior mexicano, asentó que "[...] uno de los hilos conductores de la política exterior de México en el siglo XxI debe ser la promoción y la protección de los derechos humanos en México y en el mundo". El programa de política exterior presentado poco después de la elección en la cual Fox resultó triunfador indicó que el PRI había aplicado inadecuadamente o malinterpretado el principio de no intervención. Estos conceptos aparentemente heréticos eran en buena medida producto del trabajo conjunto de los dos principales asesores de Fox en materia de política exterior: Adolfo Aguilar Zínser y Jorge G. Castañeda, personajes que a la postre ocuparían importantes cargos en el gobierno foxista. Aún más, el papel más activo que el candidato triunfador planeó para nuestro país quedó de manifiesto en los cinco meses transcurridos entre la elección y la toma de posesión, periodo en el cual Fox llevó a cabo, como ningún antecesor suyo lo había hecho, una intensa actividad internacional.

Fox viajó como presidente electo primero a Sudamérica -Argentina, Brasil, Chile y Uruguay-, y después a Norteamérica - Canadá y Estados Unidos-. Por esto en las relaciones exteriores de nuestro país —en particular - se esperaban cambios importantes con el nuevo gobierno. Como escribió Luis Rubio en Nexos de agosto de 2000, "México tendrá que experimentar una verdadera revolución en su política exterior". De manera similar, el mes en que se estrenó como canciller, Castañeda publicó un artículo en la misma revista en el que anunció que a pesar de que "[...] la política exterior es el resultado de un complejo juego de continuidad y cambio", el énfasis del nuevo gobierno estaría en el cambio.

Así pues, en el Plan Nacional de Desarrollo (PND) 2000-2006 el nuevo gobierno se fijó cinco objetivos estratégicos de política exterior: 1. Promover y fortalecer la democracia y los derechos humanos como bases fundamentales del nuevo sistema internacional; 2. Fortalecer nuestra capacidad para proteger y defender los derechos de todos los mexicanos en el extranjero; 3. Intensificar la participación e influencia de México en los foros multilaterales con un papel activo en el diseño de la nueva arquitectura internacional; 4. Utilizar los esquemas de concertación regional para equilibrar la agenda de política exterior mexicana mediante nuevos ejes de acción política; y 5. Apuntalar y encabezar los esfuerzos de promoción económica, comercial y cultural, y de la imagen de México en aras de un desarrollo nacional sustentable y de largo aliento. Cabe anotar que el primer objetivo aparecía como el quinto y último de los objetivos de política exterior del gobierno de Ernesto Zedillo — listado en cuarto y quinto lugar de ocho "grandes temas mundiales"-, que una versión similar del segundo objetivo foxista aparecía como el cuarto objetivo de la administra- 
ción zedillista y que el tercero del PND de Fox, en una versión similar, aparecía como el segundo en el PND del último gobierno priista. En este sentido, ciertamente se percibía continuidad y cambio en los albores del gobierno de la alternancia.

Ya en el ocaso del primer gobierno panista se aprecia claramente que la agenda cubierta por Tlatelolco es extensa, desde la creación-aunque, de nuevo, inspirado en un programa existente - del Plan Puebla Panamá hasta la obtención de un asiento en el Consejo de Seguridad de las Naciones Unidas — lo cual ya había sucedido en 1946 y 1981-, incluyendo una revaloración de la Organización de Estados Americanos - la cual agregó la suscripción de su Carta Democrática y la fallida candidatura de Eugenio Derbez a su Secretaría General-, el retiro unilateral del Tratado Interamericano de Asistencia Recíproca, el tema migratorio con Estados Unidos o la mediación en Colombia. De particular visibilidad resultaron las reuniones internacionales obtenidas, como la Conferencia Internacional para el Financiación del Desarrollo, que tuvo lugar en Monterrey en marzo de 2002; la Cumbre del Mecanismo de Cooperación Asia Pacífico en octubre del 2002, en Los Cabos; la v Reunión Ministerial de la Organización Mundial del Comercio, en Cancún en septiembre de 2003; la Cumbre Extraordinaria de las Américas, en Monterrey, en enero de 2004, y la III Cumbre América Latina y el Caribe-Unión Europea, en Guadalajara en mayo de 2004.

En todo caso, lo que interesa destacar aquí son los elementos más conspicuamente novedosos de la diplomacia mexicana durante el gobierno foxista, a fin de considerar hasta qué punto son indicativos de cambios sustantivos en la política exterior de México. Más que el acentuado activis- mo internacional per se, el cual podría argumentarse que tuvo un precedente en las administraciones de Luis Echeverría y Carlos Salinas, dos áreas aparecen como portadoras de cambios significativos: derechos humanos y democracia, y la relación con Estados Unidos.

El énfasis puesto por la administración foxista en los derechos humanos y la democracia tiene su origen en la legitimidad del nuevo gobierno. Como lo expresó Fox en un discurso pronunciado en Madrid en mayo de 2002: "La actual política exterior mexicana es el reflejo externo del mandato de cambio expresado en las urnas". En el mismo PND se señala que: "La nueva legitimidad democrática que hoy disfruta el país, debe servirnos como vehículo para llevar al exterior una visión de un México renovado". La conexión entre la política interna, enmarcada en un contexto de normalidad democrática, y la política externa, en el contexto de un mundo globalizado y con una clara hegemonía estadounidense, era clara. En la perspectiva del canciller y el presidente se abría una ventana de oportunidad para canjear lo que denominaron el "bono democrático". Como lo planteó Fox todavía como candidato: "Políticas y usos democráticos darán paso a una renovada confianza y una renovada ambición en nuestras acciones y negociaciones internacionales".

Pero la relación entre el ámbito interno y el externo no quedaba allí. El objetivo no era sólo colocar el "bono democrático" - cuya bursatilidad estaba todavía por verse- en el exterior, sino también aprovechar la mayor inmersión de México en el exterior para cimentar el cambio al interior del país. Como lo expresó Castañeda en un desayuno ofrecido en junio de 2002 a los miembros del Servicio Exterior Mexicano: "El punto central es la posibilidad de que la 
política exterior mexicana permita anclar el cambio democrático en nuestro país". Así pues, el reciente activismo mexicano en derechos humanos y democracia está íntimamente ligado con la alternancia surgida hace seis años.

De esta manera, en su discurso inaugural como canciller, Castañeda anunció el establecimiento de una embajada para los derechos humanos, proponiendo como su titular a una activista de larga trayectoria en el ámbito de los derechos humanos, Mariclaire Acosta. Si bien la propuesta original no se concretó, pues el senado mexicano objetó otorgar el rango de embajadora a alguien que no tendría jefe de Estado a quien presentara sus cartas credenciales, se creó en Tlatelolco la Subsecretaría de Derechos Humanos. Más allá de los errores conceptuales en la creación de esta nueva cartera, y de las pifias que el gobierno de Fox pudo haber cometido al desplegar una activa política internacional de derechos humanos, lo cierto es que demostró consistencia en la materia. Así, por ejemplo, al inicio de su administración Fox extendió a las Naciones Unidas una invitación permanente para el envío de relatores de derechos humanos a nuestro país: una clara señal de que México estaba comprometido con el respeto de estas prerrogativas fundamentales tanto en su territorio como en el exterior. No puede haber democracia sin respeto a los derechos humanos. Como señaló el sucesor de Castañeda, Luis Ernesto Derbez, en un artículo publicado en la Revista Mexicana de Política Exterior en 2003, "[...] los derechos humanos son un elemento fundamental para fortalecer y nutrir nuestra democracia".

Cabe notar que este reconocimiento llegó tarde, pues México se encontraba francamente desfasado del resto de la comunidad internacional. El fin de la Guerra
Fría y la creciente integración con nuestro vecino del Norte hacían un anacronismo de varias de nuestras posiciones centrales en política exterior. El cambio en esta materia, leit motiv de nuestra transición, fue gradual. Así, por ejemplo, en las elecciones de 1994 Salinas autorizó de última hora el ingreso de observadores internacionales, y tres años más tarde Zedillo firmó a regañadientes un Acuerdo Económico con la Unión Europea que incluía una "cláusula democrática”. La importancia de los valores democráticos y los derechos humanos empezó a permear a los últimos gobiernos priistas. Pero, en tanto la fuerza motriz de estos cambios fuera una especie de "gaiat$s u$ " o presión externa, como en buena medida era el caso, aquellos estaban destinados a ser penosamente paulatinos.

Con el ascenso al poder de la oposición, las transformaciones en esta materia adquirieron momento. Señal de ello es que México no sólo es uno de los 47 miembros del recién creado Consejo de Derechos Humanos de la onU, sino su primer presidente. Esta distinción reconoce la política —interna y externa - en esta materia del gobierno foxista - lo cual no quiere decir, como los recientes sucesos en Atenco lo demuestran, que los derechos humanos se respeten plenamente en nuestro país-; aún más, el reconocimiento es extendido no sólo por el organismo intergubernamental y otros Estados, sino también por organismos civiles líderes en la materia como Human Rights Watch. El gobierno de México ya había expuesto ante la anterior Comisión de Derechos Humanos de la ONU que los derechos humanos fueran considerados valores universales y absolutos más importantes que la soberanía nacional.

De manera similar, México suscribió en septiembre de 2001 la ya mencionada Carta Democrática de la oEA, la cual define 
la relación entre democracia y derechos humanos, y establece que cualquier disrupción no constitucional al orden democrático en un Estado miembro constituye un "obstáculo insuperable" para la participación del gobierno de ese país en el organismo regional. Además, México ha desarrollado una labor activa en apoyo de la democracia representativa, como lo hizo al condenar, junto con otros países latinoamericanos y contra la posición inicial de Estados Unidos, el fallido golpe de estado en Venezuela contra Hugo Chávez en 2002.

La otra área en la que ha ocurrido un cambio significativo en la política exterior de nuestro país es la relación con Estados Unidos. Aunque aquí —otra vez- habría que hacer notar que dicha transformación ya se anunciaba desde años atrás. Desde mediados de la década de los ochenta, en que México cambia su modelo de desarrollo, de uno prácticamente cerrado a otro más abierto, el acercamiento con Estados Unidos se profundiza. Esta proximidad no se da - por supuesto- de manera mecánica o uniforme en todas las áreas temáticas, pero sí se empieza a observar una tendencia hacia la convergencia en la agenda bilateral. Esta convergencia compartimentalizada, en la que predomina la temática económica, se acrecienta con el fin de la Guerra Fría, pues al aumentar el peso relativo de nuestro vecino del Norte en la economía política internacional, se incrementa también su ascendiente sobre nuestro país. La culminación de este proceso de convergencia, todavía predominantemente económica, es el Tratado de Libre Comercio de América del Norte (TLCAN), el cual entró en vigor en 1994. Desde entonces, si bien México conservó la mayoría de sus planteamientos tradicionales de política exterior, el país empezó a abrirse en algunos temas, tales como el de la democracia - mencionado arriba en el contexto de la observación electoral de 1994 y el acuerdo con la Unión Europea de 1998- y el de su relación con Cuba, por poner un caso paradigmático.

Sin embargo, la alternancia de partidos en el gobierno viene a marcar un cambio importante en lo que ya parecía ser una tendencia de largo plazo. El equipo de política exterior de Fox tenía un plan más o menos bien articulado respecto a lo que sería la agenda con sus vecinos del norte, fundamentalmente con Estados Unidos. El plan se resumió en el "NAFTA Plus". Como su nombre en inglés lo sugiere, el plan consistía en un TLCAN mejorado, inspirado en el esquema de integración que dio origen a la Unión Europea. Consecuentemente, el planteamiento incluía mayor movilidad laboral y fondos de convergencia para las áreas menos desarrolladas, esto es, fundamentalmente para el sur de México. Como se mencionó arriba, Fox visitó Canadá y Estados Unidos todavía en su calidad de presidente electo, en donde adelantó su propuesta de una mayor integración norteamericana basada en su NAFTA Plus. Aunque su propuesta fue cortésmente rechazada por Jean Chretién y Bill Clinton, entonces mandatarios de Canadá y Estados Unidos, respectivamente, el futuro jefe del Ejecutivo mexicano por lo menos tomó la iniciativa en la agenda trilateral.

El futuro de la relación bilateral con Estados Unidos pareció mejorar luego de la cuestionada victoria de George Bush en las elecciones de noviembre de 2000. Así, por ejemplo, el primer viaje internacional del nuevo presidente estadounidense fue a México, en febrero del 2001, y Fox fue el primer jefe de Estado en ser recibido por Bush. Una estrategia fundamental en los albores de esta relación fue el "bono democrático". La legitimidad democrática del 
nuevo gobierno se utilizó como argumento tanto para la profundización del TLCAN, en particular para el ansiado acuerdo migratorio que luego se convertiría en la "enchilada completa", como para el deseo de dar por terminado el proceso de certificación en la lucha contra las drogas en el Congreso estadounidense. Así, por ejemplo, Jesse Helms, el poderosísimo halcón jefe del Comité de Relaciones Exteriores del Senado estadounidense, cambió su trato hacia México e influyó en la terminación de la certificación a nuestro país en 2002. Aunque la profundización del TLCAN y el acuerdo migratorio no se materializaron, o al menos fueron severamente diluidos, desde el punto de vista de la concepción de la política exterior mexicana siguen siendo relevantes: por primera vez en mucho tiempo, México fijó la agenda. Todavía a principios de septiembre de 2001 la relación entre Bush y Fox era inmejorable, y el segundo se atrevía sugerir a su homólogo, en visita oficial a Washington, la legalización a corto plazo de tres millones de mexicanos.

Por supuesto que después vinieron los ataques terroristas del 11 de septiembre y sus nefastas consecuencias no sólo para Estados Unidos sino también para la política mundial —incluida la relación bilateral que nos ocupa-. A partir de entonces, como es bien sabido, no sólo ésta se enfrió, sino que Washington se obsesionó en promover su estrecha agenda de seguridad, prácticamente desentendiéndose por unos años del asunto migratorio y del desarrollo de su vecino del Sur. Así, seis meses después de los primeros ataques externos en suelo estadounidense desde Pearl Harbor, cuando Bush y Fox se encontraron en Monterrey en el marco de la cumbre para el desarrollo, firmaron el Plan de Acción para la Cooperación sobre Seguridad Fronteriza, documento que poco tenía que ver con la agenda impulsada originalmente por el mandatario mexicano. $\mathrm{Al}$ año siguiente, en marzo también, tocó a Bush ser el anfitrión de sus dos homólogos norteamericanos en Waco, Texas, donde lanzaron el proyecto de la Alianza para la Seguridad y la Prosperidad en América del Norte. De nueva cuenta, el énfasis se pone en la "seguridad" fronteriza, más que en la "prosperidad", es decir, en la mejoría de las condiciones de vida en el país más pobre de la Alianza. Ha surgido, pues, una profundización de la integración fundamentalmente en los términos dictados por Estados Unidos.

Esto no quiere decir, por supuesto, que la política exterior mexicana se haya puesto al servicio de Washington. Ahí está como muestra la posición adoptada por México en el caso de la embestida estadounidense contra Irak: dejó en claro que el apoyo mexicano tenía límites bien marcados. El discurso de Fox televisado en cadena nacional en vísperas del inicio de las hostilidades, en que el presidente lamentaba el ultimátum unilateral de Estados Unidos, y reconocía abiertamente que los dos países diferían en ese tema, ilustra este punto. Entonces, a pesar de que la nueva posición de Tlatelolco respecto a Washington parece haber sido una empresa fallida al menos en lo que se refiere a la consecución de sus objetivos más conspicuos, el hecho es que la presencia en Los Pinos de un mandatario surgido de un partido diferente al PRI trajo consigo - para bien o para mal- un trascendental cambio en la relación bilateral más importante para México. Si bien este cambio estaba prefigurado, la alternancia tuvo un efecto decisivo en su profundización. Así pues, la política exterior del gobierno foxista, en términos generales, no desentona con el extenso y anticlimático tenor del proceso de transición y consolidación de la democracia en México. my

MÉXICO YLACUENCADEL PACÍFICO vol. 8, núm. 26 / septiembre-diciembre de 2005 